

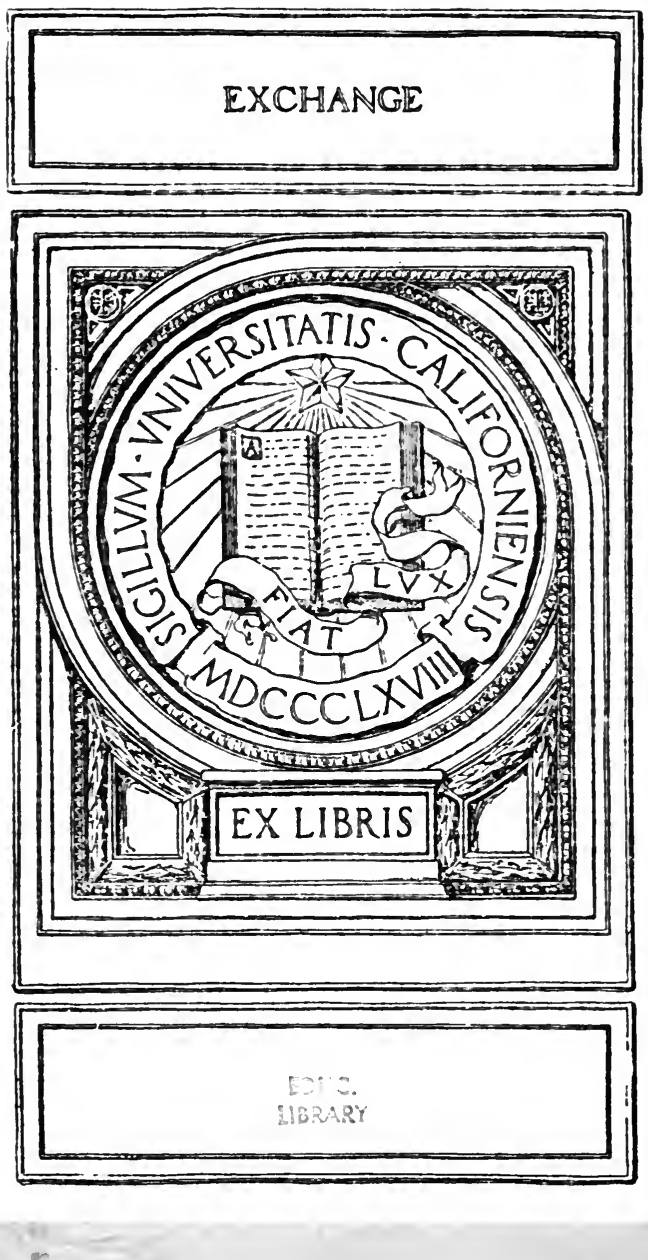
Digitized by the Internet Archive in 2007 with funding from Microsoft Corporation

http://www.archive.org/details/rationalbasisfor00smitrich 



\section{STUDIES IN EDUCATION}

FROM THE

\section{DEPARTMENT OF EDUCATION}

OF

THE STATE UNIVERSITY OF IOWA 


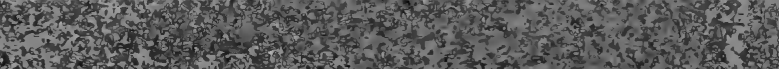

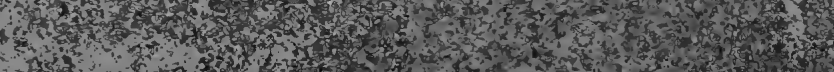

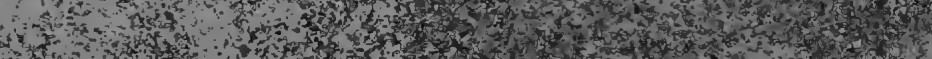

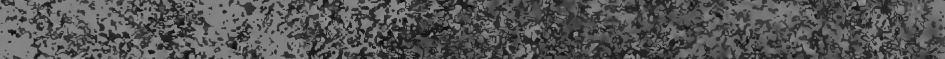

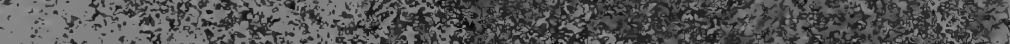

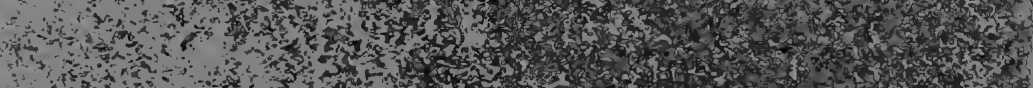
f

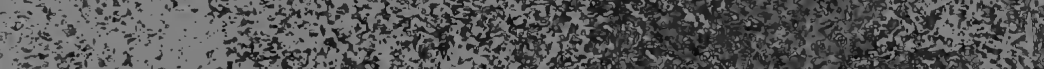

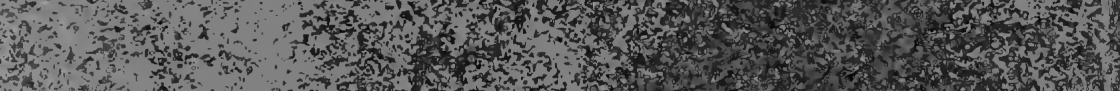
1.

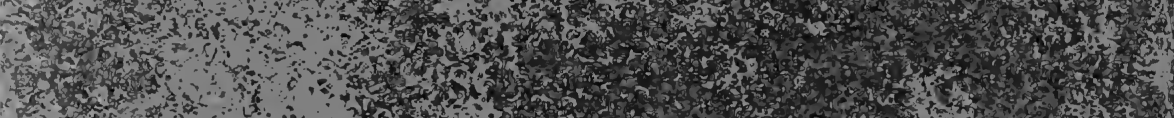

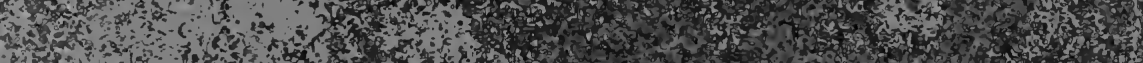

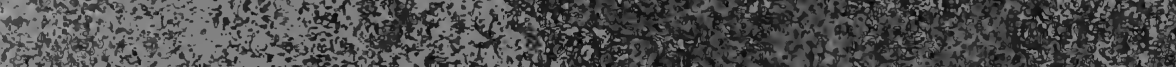

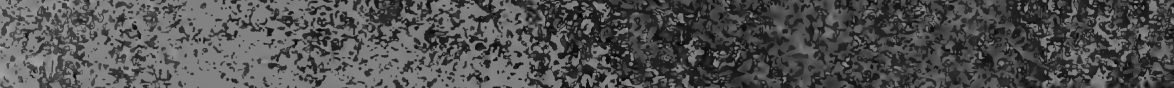

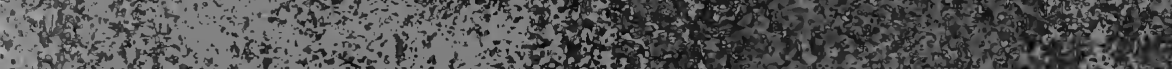

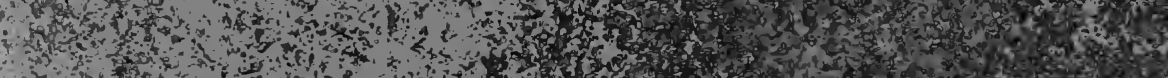

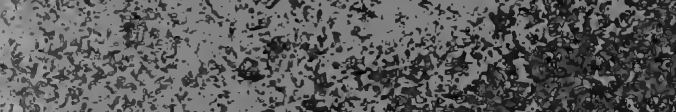

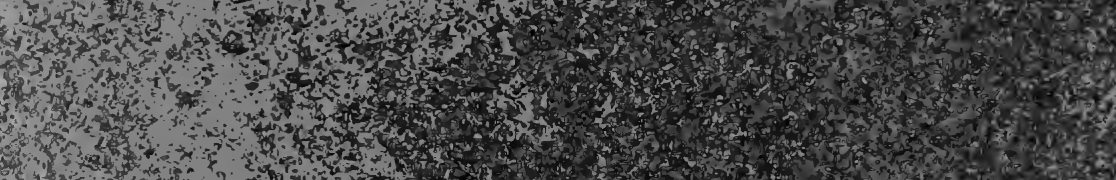

in.

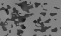

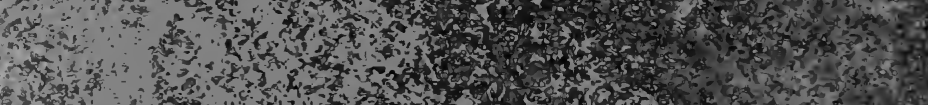

एका को

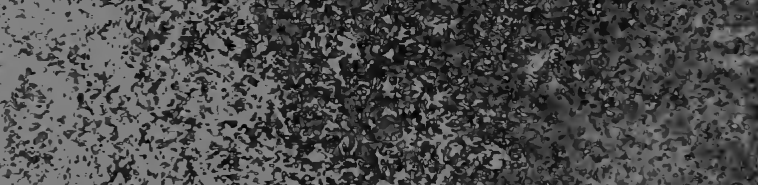
r.

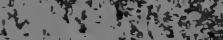

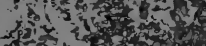
of

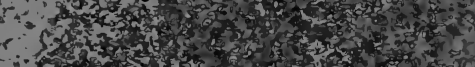
(1)

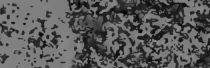

1.3.

-

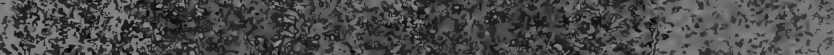

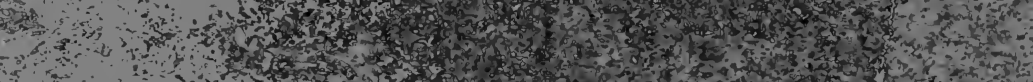

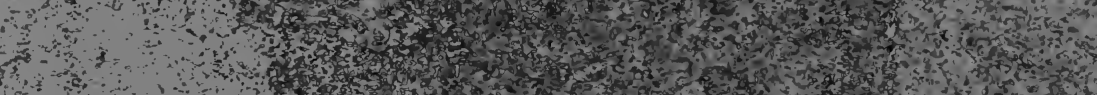

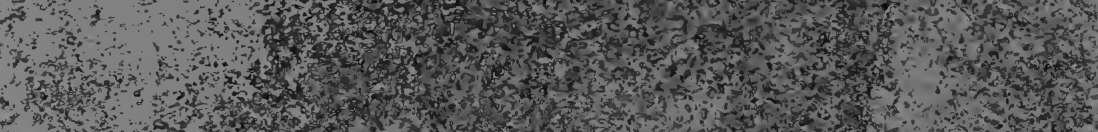

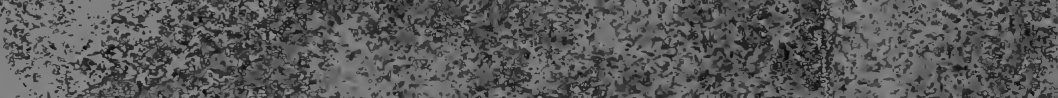

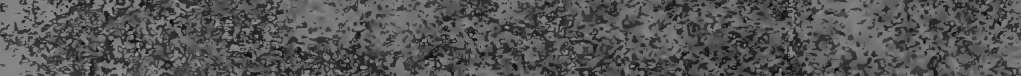

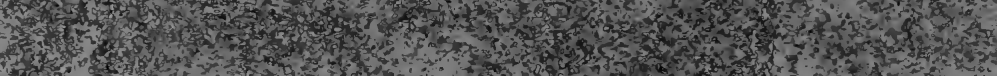

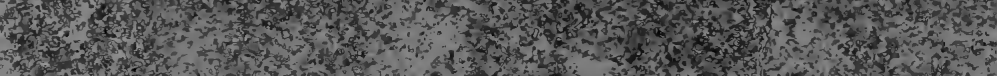

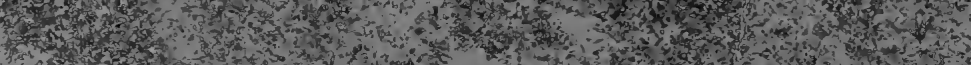


BULLETIX OF THE STATE UNIVERSTTY OF IOWA

\section{STUDIES IN EDUCATION}

FROM THE

\section{DEPARTMENT OF EDUCATION \\ OF}

THE STATE UNIVERSITY OF IOWA

- Professor Frederick Elmer Bolton, Ph.D., Editor

NOMBER 3

\section{CONTENTS}

A rational basis for determining fitness for college entrance

FrankLIN O, SMITH, M.A.

PUBLISHED BY THE UNIVERSITY

IOIVA CITY 


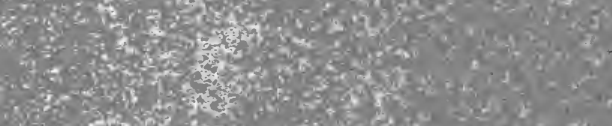

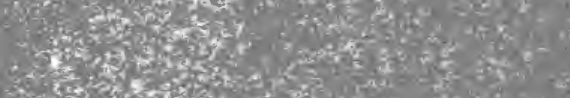

2.

(1)

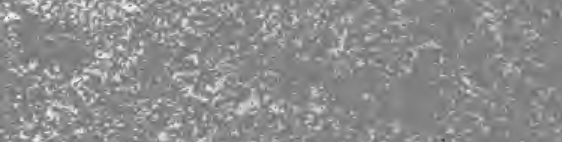

8

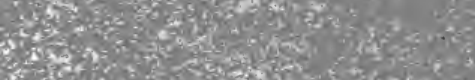

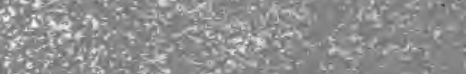

s.

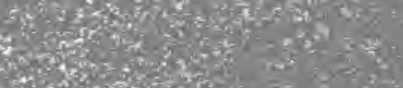

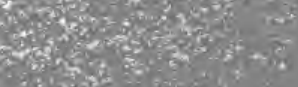

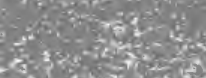

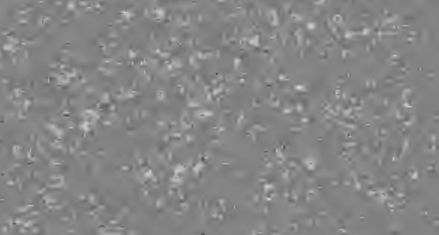

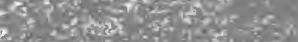
W 
IN THE SERIES OF RESEARCH BULLETINS OF THE UNIVERSITY

\section{STUDIES IN EDUCATION}

FROM THE

\section{DEPARTMENT OF EDUCATION}

OF

THE STATE ÚNIVERSITY OF IOWA

Professor Frederick Eimer Bolton, Ph.D., Editor 


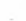




\title{
A RATIONAL BASIS FOR DETERMINING FITNESS
}

\section{FOR COLLEGE ENTRANCE ${ }^{1}$}

\author{
By FrankLin O. Smith \\ The State University of Iowa
}

The present practice of accrediting high schools in vogue in the Middle West raises the question: What should be regarded a fair basis for determining the fitness of high school graduates for entrance to college? Should it be a system of marks, absolute or literal, based upon oral or written tests or set examinations, or should it be a descriptive statement based upon the combined judgments of all the teachers stated qualitatively? The plan of accrediting high schools frankly accepts the judgment of the high school teacher as regards the fitness of her pupils to enter upon college work. On the other hand, it must be recognized that the teacher's judgment is a variable standard. It is influenced by personal equation, by the kind of marking system used, by the teacher's interpretation of the marking system, by the basis of the marks, whether examination, daily recitation, or otherwise, and sometimes by other factors than scholastic attainment, as deportment and general attitude of pupils. Teachers differ widely as to their conception of the dignity of the work required by the high school. Some emphasize the content, others the formal aspect of education, while often no account is taken of the variation in the mental constitution of the pupils. Furthermore, it should be borne in mind that by any system of marking based on achievement it is more difficult to apply the standard of grading to the bright and to the dull than to the mediocre pupils. The language of mediocrity is a common language which is easily interpreted. Precocity, on

\footnotetext{
${ }^{1}$ Communicated from the Department of Education, The State University of Iowa.
} 
the cther hand, is often an illusion, the real fact being covered up by a linguistic facility which is too often regarded as a mark of ability. Dullness is subject to the opposite illusion; the pupil that the teacher regards as dull may lack only the ability to express himself in the traditional, i. e., the mediocre way. Precocity and dullness are unique and require unique modes of expression. These the ordinary marking systems entirely overlook.

It is a fair question to ask whether, after all, those students in the high school who are classified as very good and excellent, or only fair and poor, will not maintain their relative standing in the university. Professor W. F. Dearborn ${ }^{1}$ from a study of eight large and fuur small high schools of Wisconsin answers the question in the affirmative. He concludes that three-fourths of the students who enter the university from the high schools which he studied will maintain throughout the university approximately the same rank which they held in the high school. He says that there is no reason to believe that the standards prevailing in the university differ materially, if at all, from those maintained in the best high schools of the state. The fact that Professor Dearborn's investigation was concerned chiefly with the large high schools leaves out of consideration over 90 per cent of the students who enter college from the Middle West. This fact would seem a sufficient reason for making a further study in the direction which Professor Dearborn has so well indicated.

The object of the present study, however, is to consider the question which was raised at the beginning of this paper.

The data were obtained from the office of the Registrar of the State University of Iowa and consisted of the high school and university marks of 120 Liberal Arts students, graduates of igro. About 40 members of the class were rejected because their high school records were incomplete or not on file.

The various systems of marking made use of in different high schools and in the University had first to be equated. The following method of equating was adopted as corresponding as nearly as possible to the normal curve of distribution. The scheme will be seen best if viewed in parallel columns.

$\begin{array}{ccc}\text { High school } & \text { University } & \\ \mathrm{E}=97 & & \mathrm{~A}=97 \\ \mathrm{G}=9 \mathrm{I} & \mathrm{A}=95 & \mathrm{~B}=9 \mathrm{I} \\ \mathrm{M}=85 & \mathrm{~B}=85 & \mathrm{C}=85 \\ \mathrm{P}=79 & \mathrm{C}=75 & \mathrm{D}=79 \\ \mathrm{~F}=73 & & \mathrm{E}=73\end{array}$

${ }^{1}$ Bulletin of the University of Wisconsin, No. 368 . 
In only a very few cases do we find absolute values above $97 \%$ or below $75 \%$. It would seem, therefore, that the above distribution compares fairly with the system of marks used by a majority of the high schools. The important fact is that the average grade is the same for all three of the numerical systems, and that the distribution is based upon the normal curve. It should be added that the grades have no intrinsic value in this study. All correlations are based on Pearson's rank difference method (cf. Whipple. "Mental and Physical Tests," p. 32.). Likewise, the distributions both in the high school and in the university are according to rank. The students in the high school were ranked on the basis of their average marks for the entire course in all subjects. The same students were then ranked on the basis of their average university marks. They were also ranked in successive years in the high school and in the university, and likewise in the various specific subjects.

When all the pupils have been ranked on this basis the rank numbers are arranged along a horizontal line, each number standing above the grade to which it corresponds. The order of rank is from the base line up and from right to left. In comparing the high school and university distributions it should be remembered that the same rank numbers are retained in the latter distribution as were received in the former. Thus it will be seen (Figures I and 2) that the pupil who ranked $I$ in the high school is numbered $I$ in the university, but to find his rank it is necessary to count from the extreme right to the position occupied by number $I$. This is seen to be 5. Hence the pupil who ranked $I$ in the high school ranked 5 in the university. Likewise, the pupil who ranked $\mathrm{I} 2 \mathrm{O}$ in the high school ranked $8 \mathrm{I}$ in the university. When the ranks have been thus distributed, each group is divided into five sub-groups or quintiles of 24 pupils each.

This method was thought to offer certain advantages over the quartile method of subdividing. It is obvious, as Professor Max Meyer points out, that nothing is to be gained by subdividing the medium group. Appropos of this subject he says :

"Little can be said in favor of subdividing the medium group. That this group is the largest is no reason for subdividing it. A strong argument against subdividing is the fact that this would bring about unjust grading of a large number of students. The curve is highest for medium ability. If we divide the area by a vertical line, we must have a large number of students nn one side differing by an almost infini- 
tesimal amount of ability from a large number on the other side."

Now by the quartile method the medium group is divided through the middle and is therefore open to the Professor Meyer's objection. On the other hand, too few subdivisions leave too wide a gap between the sub-groups. Superior ability can not be separated from medium ability by a single line, nor can medium ability be thus separated from inferior ability. Hence, such a division while not doing violence to a great number does a relatively greater injustice to a few. The transition from superior to medium and from medium to inferior ability must each be through a zone in which may be found individuals from both contiguous groups. This the quintile method accomplishes.

It may be useful to point out, furthermore, that the degree of correlation or lack of correlation between two distributions is indicated not by movement within the medium groups, but from one extreme group to the other. Movement within the medium groups may indicate very slight change in absolute marking and may even be attended by an opposite sort of achievement. In the extreme quintiles the reverse is true. A slight change in position indicates a relatively large amount of change in absolute marking. Hence, attention should be directed to the pupils in the extreme quintiles. If a large percentage of the pupils in the highest and lowest quintiles in the high school grouping remain in the corresponding quintiles in the university grouping, the correlation may be regarded as high, and vice versa if a large percentage of the pupils in one extreme quintile in the first grouping should be found in the opposite quintile in the second grouping, the correlation should be regarded as low.

Now it is obvious that if a high degree of correlation is maintained between the high school and the university, the standards and methods of the former are not far different from those of the latter, and furthermore the methods of selecting those whom the college will accept is adequate to meet the demands of the college. The thesis which the present study upholds is that the teacher's judgment without regard to any marking system is the only logical criterion by which to determine the fitness of pupils for college entrance. That this criterion is often unreliable and that the teacher's judgment should be standardized is admitted. Furthermore, it is admitted that some marking system is desirable and perhaps necessary. It should be a rational system, based upon some simple formula of distribution. Perhaps an approximation to the normal curve offers the best basis for a rational 
system. The best system is yet to be determined, and it will be determined only by standardizing the various methods now in vogue. And yet any system, however rational, is essentially mechanical. So long as the teacher is a slave to a system of marks there is no incentive to study the individual child. Once the teacher recognizes the principle that probably no class should ever conform exactly to an ideal formula of

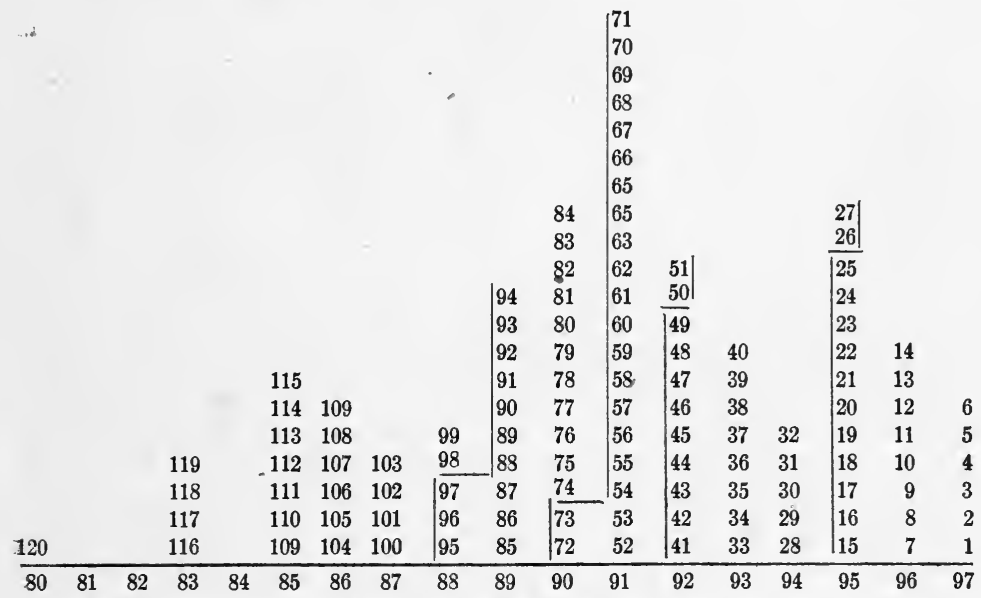

FIG. 1. Distribution of high school rankings on the basis of the general average.

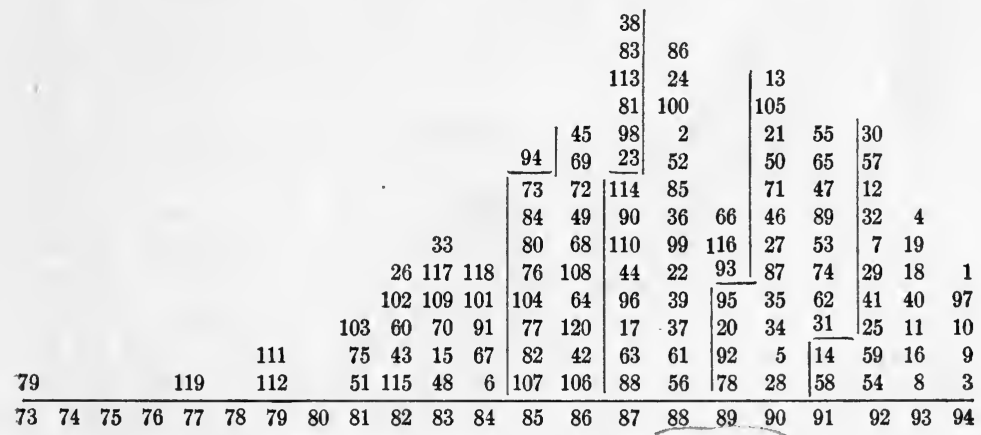

Fra. 2. The same group according to the university distribution.

marks she has a motive for interpreting the standard from every possible view point of the child. The marking system should be merely a convenient mode of expressing the teacher's judgment which should be as little hampered as possible. The view that the judgment of the teacher is on the whole a reliable criterion by which to determine the fitness of pupils 
for college entrance is shown by the facts brought out in the present study.

On the basis of the general averages in the high school and in the university it is seen (Table I, figs. I and 2) that more:

\section{TABLE I}

Distribution By QUintiles

General Averages

\section{UNIVERSITY}

\begin{tabular}{|c|c|c|c|c|c|}
\hline $\begin{array}{c}\text { High } \\
\text { School }\end{array}$ & $\underset{\%}{\text { Ist }} \mathrm{q}$ & $\underset{\%}{2 \mathrm{~d}} \mathrm{q}$ & $\underset{\%}{3 \mathrm{~d} q}$ & $4_{\%}^{\text {th }} \mathrm{q}$. & $5_{\%}^{\text {th }} \mathrm{q}$. \\
\hline Ist q. & 54 & I6.6 & I6.6 & 4 & 8 \\
\hline ...... & & 29 & 16.6 & 12.5 & 16.6 \\
\hline . ..... & 16.6 & 25 & $2 \mathrm{I}$ & 21 & 16.6 \\
\hline 4th $\mathrm{q} . \ldots \ldots \ldots \ldots$ & 0 & 25 & 25 & 33.3 & 16.6 \\
\hline 5 th $\mathrm{q} . \ldots \ldots \ldots \ldots$ & 4 & 4 & $2 \mathrm{I}$ & 29 & 42 \\
\hline
\end{tabular}

than one-half ( 54 per cent) of the pupils who were in the first: or highest quintile in the high school grouping remain in the corresponding quintile in the university grouping, and that somewhat less than half ( 42 per cent) of those in the fifth or lowest quintile in the high school grouping are in the same quantile in the university grouping. Furthermore, 29 per cent of those in the first quintile are in the upper half of that quantile, while only 16.5 per cent of those in the lowest quintile are in the lower half of that quintile. That is, I2.5 per cent more pupils move up from the lowest positions in the high school to relatively higher positions in the university than move down from the highest to relatively lower positions.

If we divide the groups into two equal parts instead of five and then proceed as before to compare the pupils' standing in each half of the high school grouping with their standing. in the corresponding half of the university grouping, the result is almost exactly identical with that found by Professor Dearborn in the larger high schools of Wisconsin. To be exact, 71.6 per cent of those who were in the first half of the high school grouping remain in the same half of the university grouping, and 70 per cent of those in the second half of the former grouping remain in the corresponding division of the latter grouping. Professor Dearborn is doubtless correct when he says, "The correlation between standings in the high. school and in the university is even closer than this rough method would seem to indicate, because ...... a change of a single grade or so near the median or dividing line between the two halves, if made by a number of individuals, would influence the composition of the two groups, materially. And it 
is likely that this frequently occurs because the majority of pupils in these distributions are centered about the median."

Equally strong evidence of the comparative stability of the two groupings is to be found in the fact that only one pupil moved up from the lowest quintile in the high school to the highest quintile in the university, and only two of those who were in the highest division in the high school were in the lowest division in the university.

Table II and figures 3, 4, 5, and 6 represent respectively the ranking of pupils in the freshman, sophomore, junior, and senior years in the university as compared with their general average high school standing (fig. I). It will be seen that the per cent of those who are in corresponding quintiles in successive years in the university as compared with the general average in the high school is about the same as that for the general average in the university. The per cent of those who change from one extreme quintile in the high school to the opposite quintile in the university is also correspondingly low. It may be of interest to note that in the freshman and junior years 40 to 55 per cent of those in the extreme quintiles in the high school grouping are in the corresponding quintiles in the university groupings, while in the sophomore and senior years only 25 to $4 \mathrm{I}$ per cent remain in the same division in the latter as in the former grouping. The significance of this fact will be considered later.

Another method of comparing the standing of these pupils consists in showing their relative distribution from year to year through the high school and the university. The pupils are ranked on the basis of the average grade for each year. The principle of distribution which was made use of in the case of the general averages is applied in this case. The rank

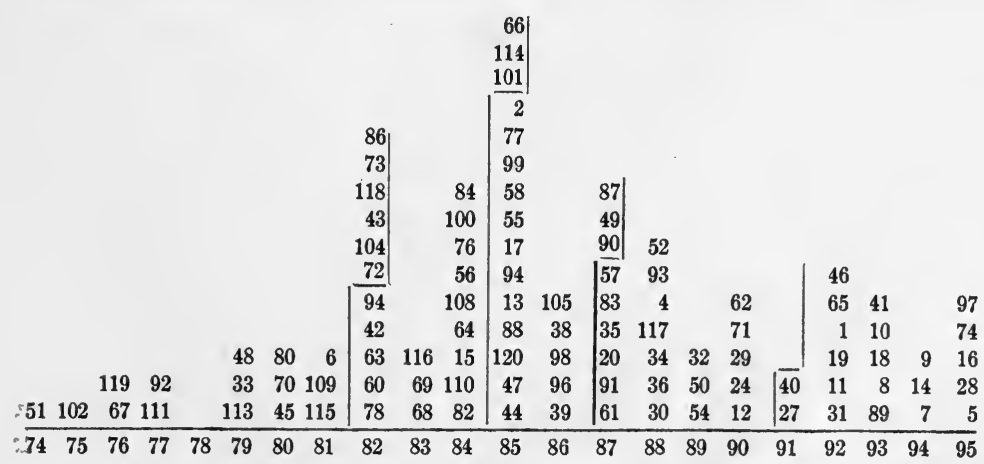

Frg. 3. Showing the distribution of ranks in the freshman year of the university as compared with the general average in the high school. 


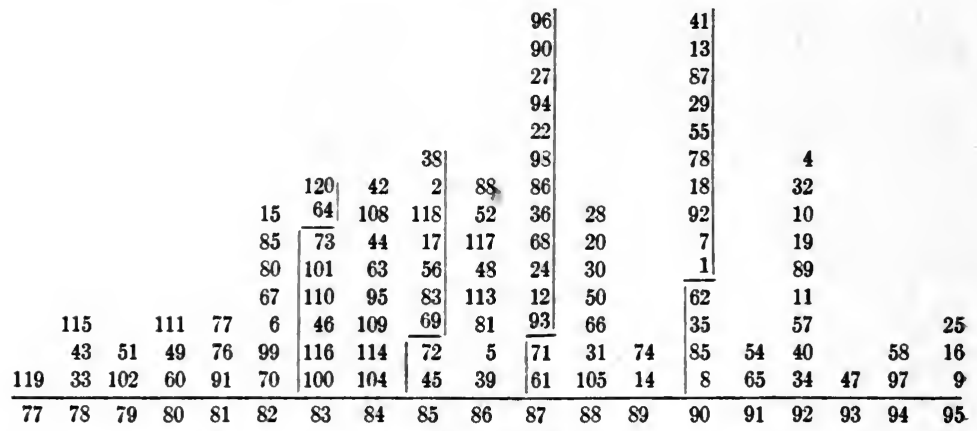

FrG. 4. Showing the distribution of ranks in the sophomore year as compared with the general average in the high school.

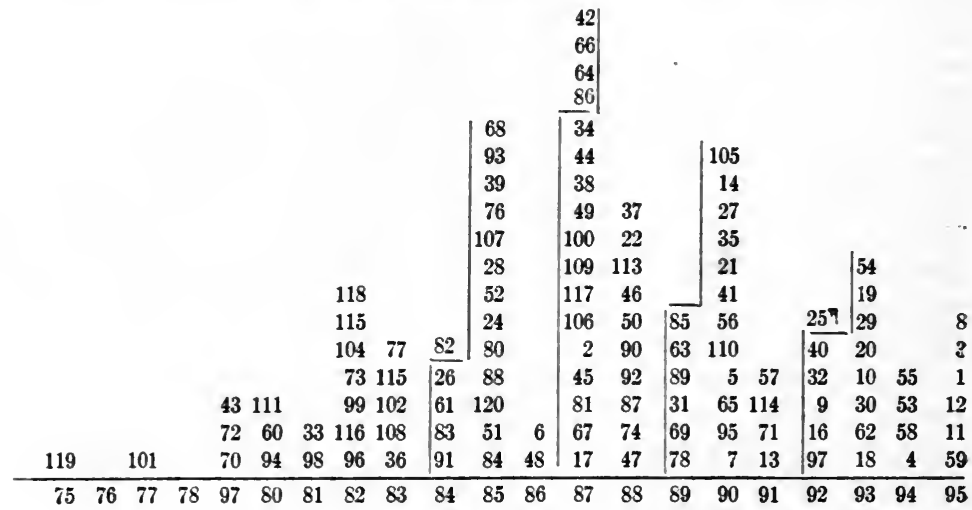

Frg. 5. Showing same distribution for the junior year.

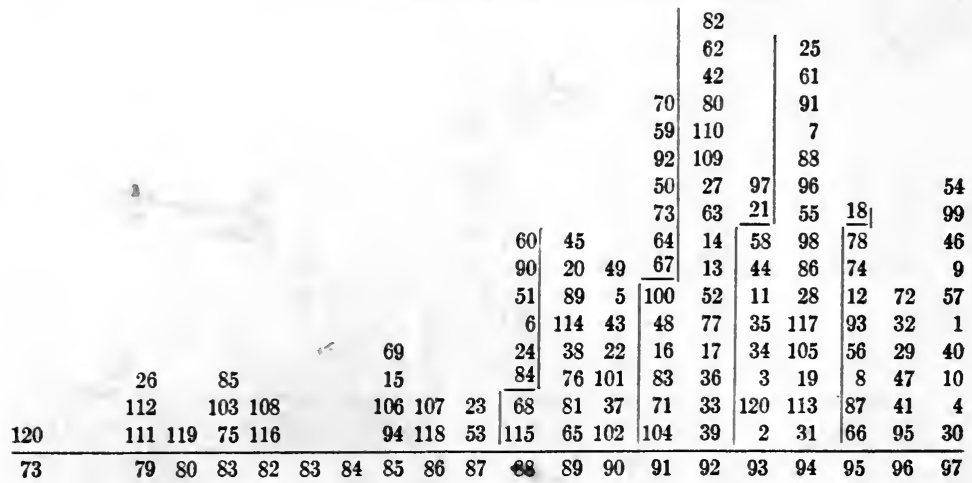

FIG. 6. Showing same distribution for the senior year. 


\section{TABLE II}

\section{Distribution By QUintiles}

High School, General Aierage. University by Years

UNIVERSITY

\section{Freshman Year}

High

School

Ist $\mathrm{q}$

$2 \mathrm{~d}$.

$3 \mathrm{~d} \mathrm{q}$

4th $\mathrm{q}$

5 th

High School

Ist q. . .............

2 d q. . ............

3 d q. . ............

4th q. . ...........

5th q.

High School

Ist q. . ............

2d q. . ............

3d q. . ............

4th q. . ...........

5 th $\mathrm{c}$

High School

Ist q. . .............

2 d q. . .............

$3 \mathrm{~d}$ q. . ............

4th q. . ...........

5th $\mathrm{q}$

$\begin{array}{ccccc}\text { Ist q. } & 2 \text { d q. } & 3 \text { d q. } & 4 \text { th q. } & 5 \text { th q. } \\ \% & \% & \% & \% & \% \\ 55 & 20 & 15 & 5 & 5 \\ 24 & 33 & 19 & 5 & 19 \\ 4.5 & 27 & 18.5 & 36.5 & 13.5 \\ 10 & 15 & 30 & 25 & 20 \\ 5 & 5 & 20 & 30 & 40\end{array}$

Sophomore Year

$\begin{array}{ccccc}33 & 28.5 & 19 & 9.5 & 9.5 \\ 26 & 22 & 22 & 17 & 13 \\ 24 & 24 & \text { I4 } & \text { 14 } & 24 \\ 9.5 & 19 & 33 & 14.5 & 24 \\ 5 & 5 & 15 & 45 & 30\end{array}$

\section{Junior Year}

$\begin{array}{lllll}54.5 & 23 & \text { I3.5 } & 9 & \\ \text { I7.5 } & 22 & 30 & 17.5 & \text { I3 } \\ 23 & 23 & 19.5 & 23 & \text { II.5 } \\ \text { O } & \text { I9 } & \text { I9 } & 38 & 24 \\ 4.5 & \text { I3 } & 21.5 & 8.5 & 52.5\end{array}$

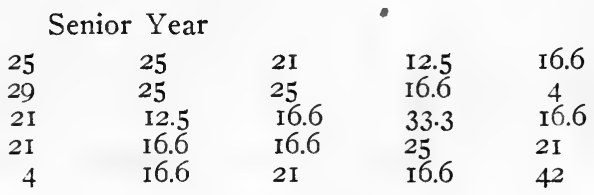

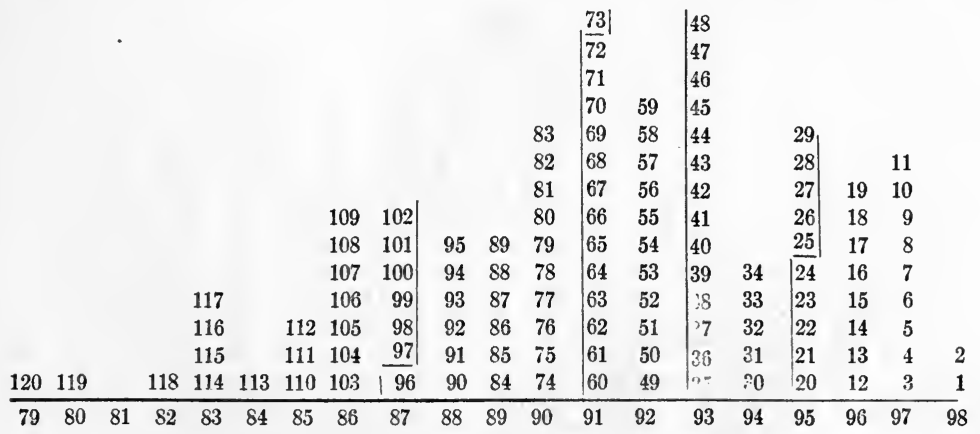

FIg. 7. Distribution of first year high school ranks. 


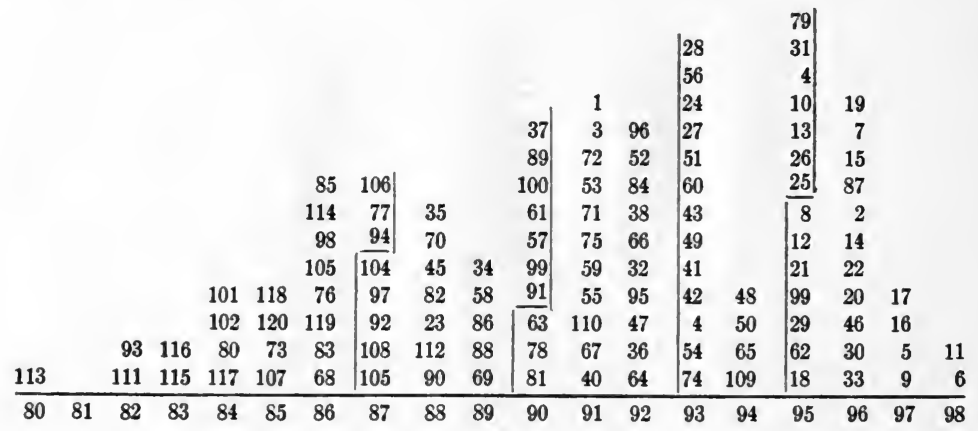

Fic. 8. Same group according to second year high school distribution.

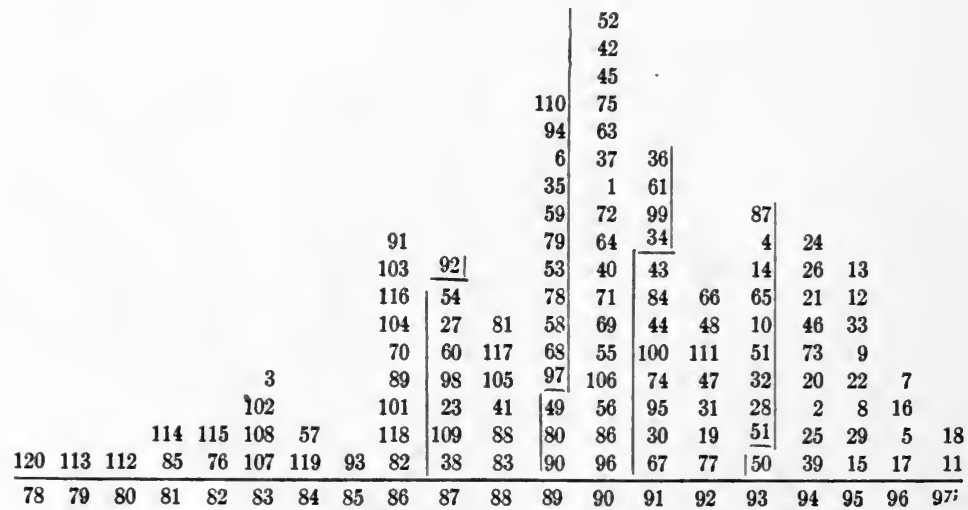

FIG. 9. Same group (fig. 7) according to third year high school distribution.

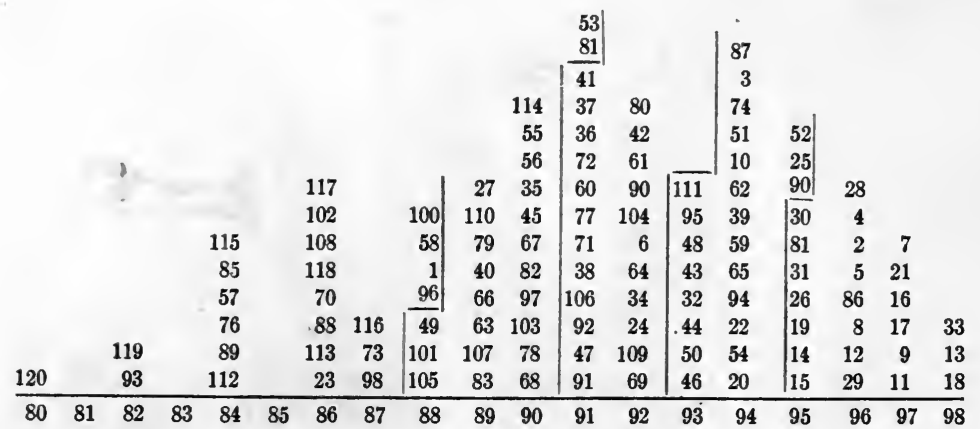

FIG. 10. Same group (fig. 7) according to fourth year high school distribution. 


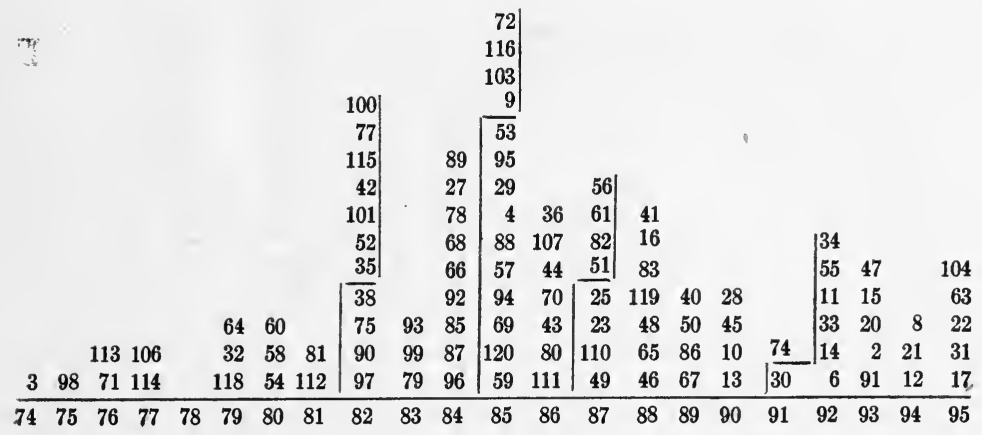

Fig 11. Same group (fig. 7) according to freshman university distribution.

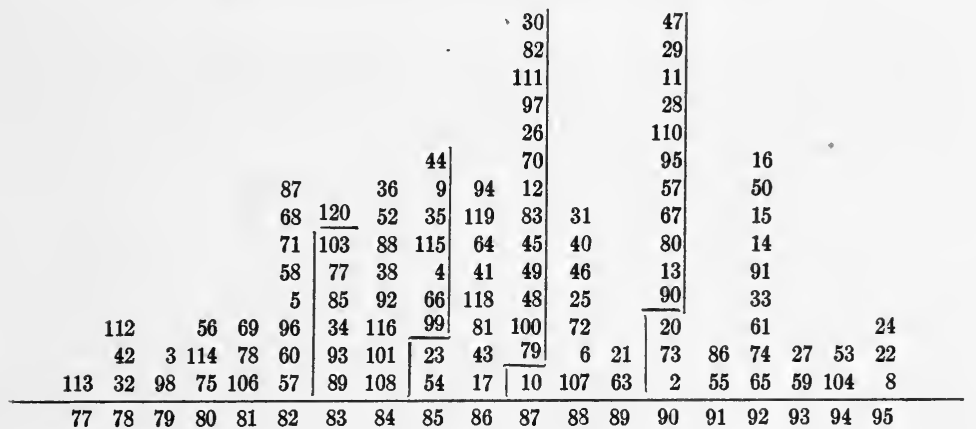

Fra. 12. Same group (fig. 7) according to sophomore university distribution.

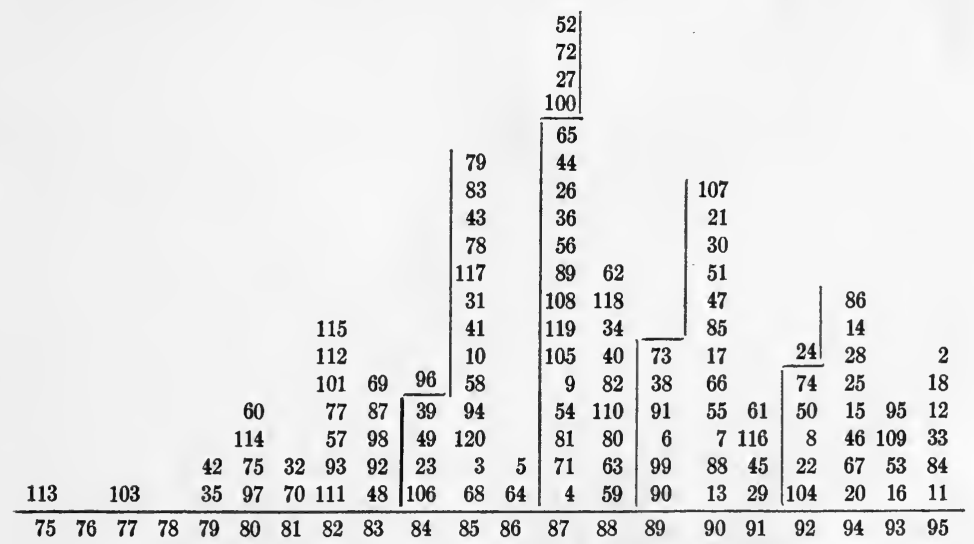

Fra. 13. Same group (fig. 7) according to minor university distribution. 


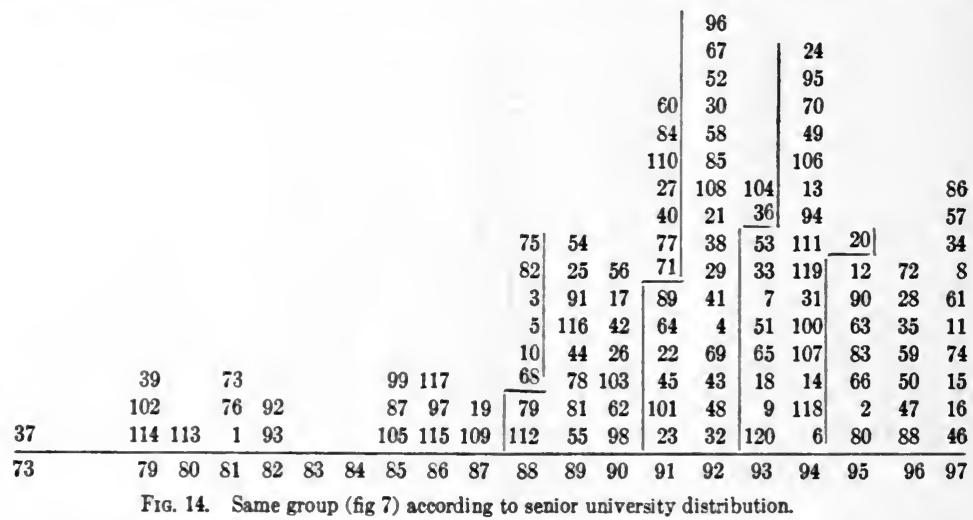

numbers which were received in the first year in the high school are retained throughout the high school and university courses. In this way it is possible to trace the standing of each pupil from the time he enters the high school until he graduates from the university (Table III, and figures $7,8,9$, 10, II, I2, I3, and 14).

This, it must be admitted, is a more rigid test of correlation than the two previously described. To maintain a given standing year by year throughout the high school and university courses is a better indication of high correlation than to maintain the same standing on the basis of the general average. In this as in the other comparisons the extreme positions are of special significance. The per cent of those who remain in the same quintile in successive years is shown in table III. Just one-fourth of the pupils who enter the high

\section{TABLE III}

Distribution (by Quintiles) of First Year High School Pupils Through the High School and the University

\begin{tabular}{|c|c|c|c|c|c|c|c|c|}
\hline \multirow[b]{2}{*}{ Year } & \multicolumn{4}{|c|}{ High School } & \multicolumn{4}{|c|}{ University } \\
\hline & I & 2 & 3 & 4 & I & 2 & 3 & 4 \\
\hline 2 & $\%$ & $\%$ & $\%$ & $\%$ & $\%$ & $\%$ & $\%$ & $\%$ \\
\hline rst q. . & 100 & 70 & 67 & 67 & 52 & 36 & 43 & 25 \\
\hline $2 \mathrm{~d}$ q. . & 100 & 54 & 33 & 29 & 35 & 33 & 22 & 8 \\
\hline 3d q. . & 100 & $4 I$ & 37 & $2 \mathrm{I}$ & 35 & 20 & 22 & $2 \mathrm{I}$ \\
\hline $4^{\text {th }} \mathrm{q}$. & 100 & 29 & 25 & $2 \mathrm{I}$ & 48 & 28 & 17 & 25 \\
\hline 5 th $\mathrm{q}$. & 100 & 59 & 59 & 50 & 45 & 32 & 39 & 37.5 \\
\hline
\end{tabular}

school as superior students graduate from the university in the same group. A few more, 37.5 per cent, who were ranked as inferior students in the first year of the high school remain in the lowest group in the senfor year of the university. On the whole, there is more fluctuation of first quintile than of 
fifth quintile pupils. The loss from the first quintile between the fourth year in the high school and the freshman year in the university amounts to 22 per cent, while only ro per cent move up from the lowest quintile in the same period. The sophomore year in the university is unique. Fewer pupils remain in the first, third, and fifth quintiles than in any other year. The senior year also represents a relatively low percentage of those remaining in first and fifth quintiles. This corresponds to what was found with reference to correlation between the general average in the high school and successive years in the university.

The general uniformity of standings through the four years of the high school course as contrasted with standings in successive years in the university is significant. The fact that these students are from small high schools where, in many cases, the school is represented by a single student is also significant. The conclusion which is forced upon one's attention is that whatever difference exists between the marking of pupils in the high school and in the university is in the direction of greater reliability of high school marks. That the standard of marking as it is interpreted by individual teachers should be more uniform in the high school than in the university is not surprising when we consider that the high school teacher comes in closer touch with her pupils than it is possible for the university instructor to do. The latter must depend largely upon the written work of the student for his marks, while the former marks upon the broader basis of personal intercourse through oral recitations, reports, and general attitude, using the written exercise as a means of checking up the personal judgment. Even the written work of the high school student is likely to be better supervised than is the same work in the university.

The break between the high school and the university is the inevitable outcome of the readjustment that accompanies the taking of the next higher step. It corresponds to the declination in the learning curve which often precedes the organization of higher intellectual processes. Just as the "stages of arrest in learning should be avoided if possible" ${ }_{1}$ so the break between any type of school and the type next above it should be reduced to a minimum.

The sophomore and senior years present a striking contrast to the freshman and junior years in the university in that a relatively small percentage of pupils remain in quintiles corresponding to those in the first high school year. The low percentages in the sophomore year must not be taken as an

${ }^{1}$ Colvin, S. S. The Learning Process, p. 43. 
indication of a low degree of correlation between this and the freshman year. It should be interpreted just the opposite. That is, a high degree of correlation exists between the freshman and sophomore years which indicates that those who stand high in the freshman year also stand high in the sophomore year, and vice versa. But the cause which produced the low correlation between the first year high school and the freshman university cannot be the same as that which brought about the low correlation between the first year high school and the sophomore university. The sophomore year marks the real beginning of readjustment. It is the time when the student is first thrown largely upon his own resources. With the privilege of electing a large portion of his course comes the consciousness of conflicting interests which often interfere with the student's best effort.

Another cause of this low correlation is the fact that the sophomore year is distinguished from the freshman by the greatly increased number of lecture courses offered. These two causes operating together make the sophomore year a critical period in the university.

The junior and senior standings are to be explained on the same general principle. The junior year marks a period of relative adjustment between the student and university methods. The student has found himself, so to speak, and has thus recovered to a certain degree his normal standing in the original group. Two forces operate to cause the fluctuation in the senior year. The senior year marks the culmination of specialization in undergraduate courses. The number of different courses pursued in the freshman year was 4.5 . In the sophomore year it was 3.8 , in the junior, 3.5 , and in the senior, 2.5. A high degree of specialization is accompanied by a correspondingly high degree of individual variation which accounts in part for the fluctuation of standings at this period. A contributing factor is to be found in the fact that the senior year is apt to be a period of diminished effort. In the present study it was observed with surprising frequency that a student who had maintained a high standing during the first three years in the university dropped to a low standing in the last year. The point to be emphasized is that the causes of fluctuation in the university are peculiar to conditions in the university and not to the unreliability of high school standards to meet college entrance requirements.

A striking illustration of the reliability of high school as compared with university markings is to be found in an examination of the relative standing of superior and inferior pupils of the first year ranking. Tables IV and V represent 


\section{TABLE IV}

Distribution of ist Quintile PUPils

\begin{tabular}{|c|c|c|c|c|c|c|c|c|}
\hline \multirow[b]{2}{*}{ Year } & \multicolumn{3}{|c|}{ High School } & & \multicolumn{4}{|c|}{ University } \\
\hline & I & 2 & 3 & 4 & I & 2 & 3 & 4 \\
\hline & $\%$ & $\%$ & $\%$ & $\%$ & $\%$ & $\%$ & $\%$ & $\%$ \\
\hline Ist q. . ......... & 100 & 70 & 67 & 67 & 52 & 36 & 43 & 29 \\
\hline $2 \mathrm{~d} q . \cdot \ldots \ldots \ldots$ & 100 & $2 I$ & I7 & I7 & 20 & 25 & 26 & 32 \\
\hline $3 \mathrm{~d}$ q..$\ldots \ldots \ldots$ & 100 & 9 & 4 & 8 & 5 & IO & 9 & I6 \\
\hline $4^{\text {th }}$ q. $\cdot \cdots \cdots \cdots$ & 100 & 0 & 8 & o & 5 & I4 & I8 & 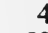 \\
\hline 5 th q..$\ldots \ldots \ldots$ & 100 & o & 4 & 8 & 5 & Io & o & 20 \\
\hline
\end{tabular}

TABLE V

Distribution of 5Th Quintile Pupils

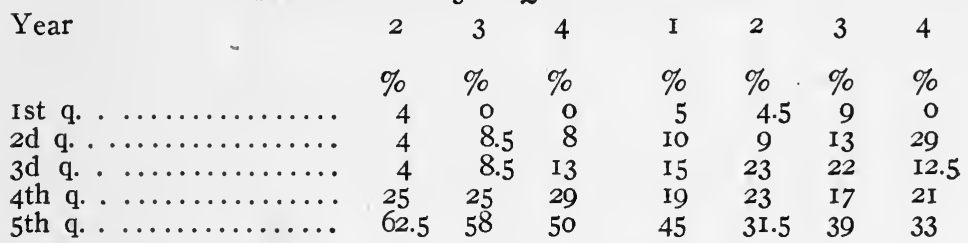

the distribution through successive years of first and fifth quintile pupils respectively. It will be seen that relatively few first quintile pupils fall below the third quintile except in the senior year when 25 per cent are in the fourth and fifth quintiles. A similar statement holds for fifth quintile pupils.

From the above illustrations whether based on general averages or on the averages for successive years it does not appear that the small high school with limited, often meagre, equipment, library facilities, and teaching force is worse fitted for preparing and selecting pupils for college than is the large and presumably the best high schools. The facts which have so far been presented are summed up in the following table of correlations. (Table VI.) It may be helpful to explain that an index of less than +.25 should be interpreted as indicating low correlation. From +.25 to +.50 means moderate corre-

\section{TABLE VI}

\section{CORRELATIONS}

General Average High School and University............. +.53

General Average High School and Freshman University......... +.48

General Average High School and Sophomore University...... +. +.39

General Average High School and Junior University........... +.47

General Average High School and Senior University.......... +...

First and Second Years High School....................... +.77

Second and Third Years High School........................ +.76

Third and Fourth Years High School..................... +.75

Fourth Year High School and Freshman University......... +.44

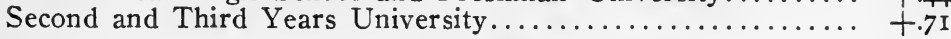


Junior and Senior Years University................. +.42

First and Third Years High School....................... +.67

First and Fourth Years High School....................... +. 66

Freshman and Sophomore Years...................... +.73

Freshman and Junior Years............................... +.6r

Freshman and Senior Years............................... +.45

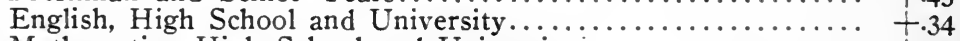

Mathematics, High School and University .................... +.29

History, High School and University...................... +.18

Ancient Languages, High School and University............. +.43

Modern Languages, High School and University................ +.28

Science, High School and University...................... +.34

lation, +.50 to +.75 , high correlation, and +.75 to $+\mathrm{I} .00$, exceptionally high correlation, I.Oo being perfect correlation. In addition to the facts already presented this table shows the correlation between specific subjects in the high school and in the university. The fact that the correlation between specific subjects is low has no direct bearing on the main question, but shows, on the other hand, a wide range of individual variation. A student may be good in all of his subjects but one in the high school which would give him a high standing. $\mathrm{He}$ may also be good in all his subjects but one in the university which would give him equally high standing there and would mean for this student high correlation. His poorest subject in the high school may, however, be his best in the university, and vice versa, which would mean a low correlation between two subjects for this student. Many similar variations are possible.

This leads to one further consideration which has some bearing on the main problem. It often happens that certain individual students who are marked consistently high in the high school receive low marks in the university, and vice versa. For example, the pupils who ranked 9, IO4, and II9 are cases in point. The first pupil was marked uniformly high by his high school teackers. During the first three years in the university this pupil was ranked below average and just above average in the senior year. The other two were considered inferior students throughout their high school course, but in the university they ranked high or above average. The second pupil, number In4, takes his place at once in the first quintile where he maintains his standing with marked uniformity through the four years. The third pupil moves up more gradually. Starting almost at the very foot of the group and never rising above the fifth quintile in the high school, he takes his place as a university freshman among the medium members of his class. He mântains his standing throughout the course, moving up gradually to within 8 of the first quintile in the senior year. 
Taking these pupils as representative of a class of students found in all colleges we may ask whether the school meets its obligation to this class. Two assumptions may be made with reference to each of these pupils. We may assume that the first pupil earned his high standing in the second and fourth years in the high school. If so, why did he not maintain an equally high standing throughout his course? On the other hand, he may have been only a low medium or inferior student, as indicated by his university standing. The opposite assumptions may be made with reference to the other pupils. If the first assumption is correct, and it doubtless is correct in many instances, then there exists somewhere in the school course a lack of adjustment between the curriculum and the individual. Somewhere in the course there was a failure to meet the first demand of public education, namely, to educate each individual up to his highest efficiency. If the second assumption is correct, the marking systems of high schools and colleges is a subject for further investigation.

The fact that three marking systems were made use of by the different schools included in this study would seem to indicate that the standing which pupils maintain in the high school and in the university does not depend so much upon the marking system in vogue in these schools as upon other considerations. More important than a system of marks is the right conception on the part of the individual teachers of the dignity of high school and college work. There should be a standard of value for each high school subject, which should bear a definite relation to college standards for the same subjects. These standards should be independent of percents or E's or A's or other symbols. They should rest upon a rational method of the distribution of ranks. Professor A. G. Smith ${ }^{1}$ thinks that for the college this should be the normal curve. Whatever ideal method is employed must be determined by investigation and must be adopted by both the high school and the university. But when this is done there still remains the problem of standardizing the teacher's judgment.

1" A Rational College Marking System." Journal of Educational Psychology. September, I9I I. Pp. 383-393. 




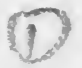

Obtainable from the University Editor

Price, $\$ 0.75$ 



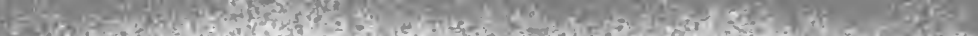

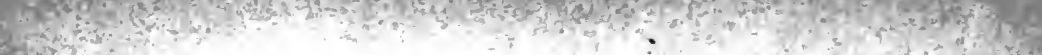
Pespin:

1, $1=0$

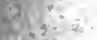

at

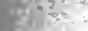

bsti:

$=\frac{1}{8}$

$\log ^{2} x^{2}=$

arting

$2: \frac{3}{2} \cdot 2$

13.

in:

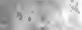

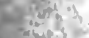

4 -

(4)

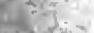

ing

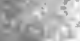

$4 x^{2}$

$4.32=$

(1) 1.9

$+8$

is

28

ictions

Mifisis

$=\frac{1}{2}+\frac{2}{3}$

$\therefore+x^{2} \cdot 3$

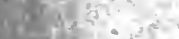

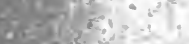

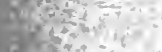

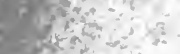

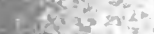

$=4 \cos 3$

Mints

$8 x^{2} x^{2}=1$

ation.

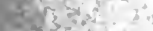

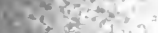

$\left.40 x^{2}\right)^{2}$

$\sqrt{4}+35^{2}$

8. 20

$x^{2}=3 \frac{2}{25}+6$

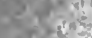

$\cos ^{2} x^{2}=$

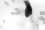

givis

$=2+b^{2}+2 i$

Poxts?

$7 x^{2}=$

is

$10 \frac{9}{6 y}$

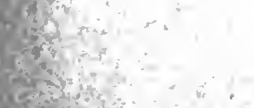

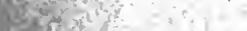

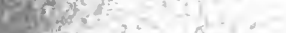

$\operatorname{lom}^{2}-\frac{3}{4}=2$

$x^{2}+x^{2}=$

$y^{2}=$

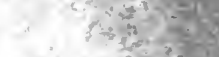

$-2+2$

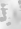

is $918=5$

20 in:

Tingeis

?

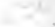

$32^{2}-1+2 y$

$-1, x^{3} x^{-12}+x^{2}$

i.2.

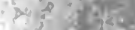

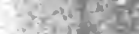

is.t 1 in

7 is

(3)

$\frac{x}{x}+\frac{1}{3}+\frac{1}{3}$

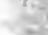

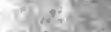

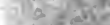

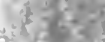

$y^{2}=x^{2}+1$

1. $3 x^{2}=1$

Mylca?

4.

(uts

- is.

$3-x_{0}-1$

ace ge?

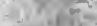

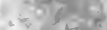

$2 x=$

$x^{2}+\frac{1}{2}$

$24,2 \pi$

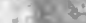

$3 x^{2}+4$

t $=8$.

1
3
$x .12$

the

$x+87$ in

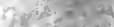

$3)^{2}+x^{2}$

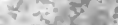

कर 20 is

$\left.x^{3}\right)^{2}$

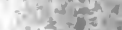

and

- if th

ret $\frac{1}{2} x$

$+45$

(t)

mith. 20

taris

a 5.512

- 253 की

$7-6 x^{2} x$

* $y=3$

$f^{2} y^{2} ?$ the

से $x+y^{2}$ ह

$x^{2} \mathrm{~A}^{4}$ है।

W

by gines

की $y=4$

a

A. तो

$1<\frac{1}{4}$

$\therefore 3^{2}+8 x$

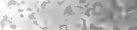

Fof 
RETURN TO the circulation desk of any

University of California Library

or to the

NORTHERN REGIONAL LIBRARY FACILITY

Bldg. 400, Richmond Field Station

University of California

Richmond, CA 94804-4698

ALL BOOKS MAY BE RECALLED AFTER 7 DAYS

- 2-month loans may be renewed by calling (510) 642-6753

- 1-year loans may be recharged by bringing books to NRLF

- Renewals and recharges may be made 4 days prior to due date

DUE AS STAMPED BELOW

\section{SEP 052003}

SEP 242003

OCT 172003 


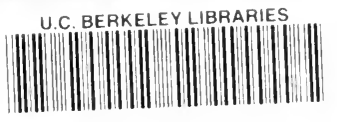

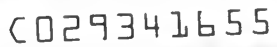

840514

UNIVERSITY OF CALIFORNIA LIBRARY

EDUC.

LIBRARY 


\section{.}

